\title{
DE LA FUTURISM LA SPECTACOLUL MULTIMEDIA CONTEMPORAN \\ Elemente în evoluția hibridității formelor artistice
}

\author{
Alexandra Călinescu-Gărniță
}

DOI 10.46522/CT.2021.02.07

\begin{abstract}
From Futurism to the Multimedia Contemporary Performance. Elements in the Evolution of the Hybridity in Artistic Forms
\end{abstract}

The mass media and the data processing system are the technologies of our modern society, being born simultaneously and developing simultaneously. I am going back to the invention of photography and the PC's precursor, continuing with the birth of cinema, to finally arrive at the modern computer, the one that blends all the information and transforms it into numeric data. Among the main influences of the contemporary performance, we find the experiments led by the modernist avant-garde at the beginning of the 20th century - futurism, constructivism, expressionism, dadaism and surrealism - while the first of these movements, the futurism, holds a central position in the contemporary performance's downward. At the end of the 20th century, computer technologies have become more and more present in theatre, dance and performance, thus shaping new dramatic forms, new types of spectacle and interactive performances. How are the new media technologies changing our visual language and what new aesthetic resources do we find as a result?

\section{Keywords:}

new media, performing arts, modernist avantgarde, hystory of multimedia performance, contemporary visual language. 
$\mathrm{N}$ e aflăm într-un plin proces de reconfigurare și redefinire a artelor spectacolului de către noile media generate de un computer, căutând să aflăm răspunsul la întrebări legate de modul în care această computerizare a culturii afectează limbajul vizual pe care îl folosim și, de asemenea, care sunt noile posibilități estetice pe care le putem avea în vedere. Computerizarea culturii aduce cu sine nașterea de noi forme culturale, redefinind practic și formele existente, ca teatrul, fotografia sau „cinemaul“.

Mijloacele de comunicare în masă și sistemul de procesare a datelor reprezintă tehnologiile complementare ale societății moderne, ele apărând deodată și dezvoltându-se în același timp. Fotografia, filmul, presa tipărită, radioul și televiziunea au făcut posibilă transmiterea către publicul larg a acelorași texte, imagini și sunete, în timp ce computerul a înlesnit ținerea evidenței datelor lor de naștere, a contractelor de angajare, a fișelor medicale sau cazierului.

În 1839, Louis Daguerre, cunoscut deja pentru dioramele sale, prezenta publicului noul proces de reproducere a imaginii denumit daguerréotype (dagherotip). Inițial, dagherotipurile înfățișau în mare proporție clădiri, însă, după o serie de îmbunătățiri tehnice, acestea au început să fie folosite pentru fotografia de portret, dând naștere unui nou tip de afacere, studioul fotografic, folosit preponderent pentru portrete de familie. În aceeași perioadă, în 1833 Charles Babbage începea lucrul la o mașină pe care o denumea Motorul Analitic, precursorul computerului modern. Acesta lucra cu o serie de carduri conținând instrucțiuni și informații care erau introduse în memoria aparatului, unde o unitate de procesare realiza operațiile asupra datelor și stoca rezultatele în memorie, acestea fiind ulterior tipărite. Motorul Analitic nu doar urmărea programul introdus pe carduri, dar și decidea care instrucțiuni să le execute și în ce ordine, în funcție de rezultatele anterioare, putând realiza astfel orice operație matematică.

În secolul al XIX-lea și la începutul secolului al XX-lea, în paralel cu dezvoltarea unor calculatoare mecanice și electrice, avea loc îmbunătățirea noilor suporturi media care permiteau stocarea imaginilor, a sunetelor și a textului: placa 
fotografică, filmul și gramofonul. În anii 1890, mass-media au făcut încă un pas înainte atunci când imaginile fotografice au devenit imagini mișcătoare, datorită primului studio de film, „Black Maria“, inițiat de Thomas Edison, unde erau produse filme scurte, cu durata a 20 de secunde, care puteau fi urmărite, individual, cu ajutorul unui aparat special denumit kinetoscop. Doi ani mai târziu, frații Lumière prezentau publicului prima cameră de proiecție cinematografică, aceasta ajungând în scurt timp să proiecteze filme în mai multe capitale ale lumii. Drumurile mass-media și ale calculatorului s-au întâlnit în cele din urmă după aproximativ 50 de ani, când dagherotipul lui Daguerre, motorul analitic al lui Babbage și cinematograful fraților Lumière s-au contopit într-un singur aparat în care toată informația - grafică, imagini, filme, sunete, forme, spațiu și text - este transformată în date numerice, respectiv într-un set de date computerizate.

Astăzi, în era informației, viața umană este invadată de tehnologie. În orice domeniu, tehnologia face parte din viața noastră, influențând felul în care ne desfășurăm cele mai simple activități. În ultima decadă a secolului XX, tehnologiile bazate pe computer au început să joace un rol dinamic și din ce în ce mai important în teatru, dans și performance, dând naștere la noi forme dramatice, noi tipuri de spectacol și instalații interactive. Oameni de teatru precum Robert Lepage sau George Coates au adus pe scenă, alături de actori, ecrane de proiecție și imagini digitale, iar compania The Gertrude Stein Repertory Theatre a încorporat inclusiv sisteme de videoconferință în reprezentațiile sale, aducând laolaltă, live, actori prezenți fizic în locuri diferite.

\section{Mass-media în construcția unui spectacol. Rolul futuris- mului în descendența performance-ului}

De-a lungul istoriei, tehnologia a schimbat modul în care umanitatea percepe viața. Fiecare invenție tehnologică este concepută pentru a face viața oamenilor mai ușoară, tehnologia aspirând să minimizeze efortul uman. În același timp, orice tehnologie, care a fost la un moment dat nouă și fascinantă, ajunge să devină obișnuită, să se integreze în viața de 
zi cu zi până în punctul în care nu ne mai putem imagina viața fără ea. În acest sens, putem spune că tehnologia schimbă modul în care oamenii percep viața.

Teatrul a fost mereu o formă de artă integrativă, incluzând în spectacolele sale muzica, dansul, pictura, sculptura, arhitectura, încorporând acum în mod firesc, în contextul „revoluției digitale“, și multitudinea de multimedia. Pentru a înțelege mai bine relația dintre tehnologie și om și pentru a înțelege modul în care această relație afectează situația socială și culturală de astăzi, ar trebui mai întâi să înțelegem ce este revoluția digitală. „Revoluția digitală“ sau „a treia revoluție industrială“ reprezintă conversia tehnologiei electronice analogice și mecanice în electronică digitală. Această schimbare își are începutul undeva la finele anilor 1950 până la sfârșitul anilor 1970; cu toate acestea, în ceea ce privește adoptarea și îmbunătățirea calculatoarelor digitale, se poate spune că revoluția digitală este încă într-un progres continuu în zilele noastre, aducând umanități inovații tehnologice importante - producția în masă, computerul, telefonul mobil și internetul, toate acestea afectând societatea sub diferite aspecte și determinând, de asemenea, unele schimbări în domeniul artelor spectacolului.

Avangarda începutului de secol XX oferă destul de multe exemple de spectacole care folosesc tehnologii pre-digitale. Artistul și coregraful german Oskar Schlemmer, aparținând mișcării Bauhaus, reprezintă un precursor important pentru multe dintre explorările în domeniul spectacolului multimedia de astăzi. Experimentând cu ideile lui Adolph Appia pe tema iluminatului, cu noțiunea de supramarionetă a lui Gordon Craig și cu propria abordare asupra spațiului, liniei și planului, Schlemmer a creat noi posibilități pentru abstractizarea coregrafiei, a narațiunii și a spațiului de desfășurare a spectacolului în anii 1920. El a creat costume „robotice" pentru dansul futurist Baletul triadic din 1922, a utilizat dispozitive mecanice cu ajutorul cărora a mutat figuri de diverse dimensiuni de-a lungul scenei pe niște fire metalice și a închis capul și mâinile uneia dintre actrițele din spectacolul Dans metalic (1929) în niște sfere metalice. Schlemmer a avut inclusiv ideea realizării unor figuri artificiale în stilul 
roboților inteligenți de astăzi, care să fie controlați de la distanță, „aproape lipsiți de intervenția umană“, și care să permită „orice tip de mișcare în orice poziție, pentru un timp oricât de îndelungat“. ${ }^{1}$

Se consideră că practica performance-ului digital începe cu mișcările de avangardă de la începutul secolului XX. Avangarda înseamnă artă inovatoare și explorarea de forme și conținut noi. La începutul secolului XX, artiștii și teoreticienii epocii au ajuns la concluzia că reprezentările artistice și conținutul textelor nu mai evocau evoluția care avea loc în societatea contemporană din acea perioadă. Astfel, ei au propus o tratare interdisciplinară a domeniului artei. Abordarea avangardistă a permis publicului să aibă o experiență mixtă oferită de colaborarea dintre artele plastice, cinema, teatru, dans și muzică în contextul unui nou tip de Performing Arts contemporan. Cu toate acestea, rădăcinile performance-ului digital datează din procedeul Deus ex machina al tragediilor antice grecești, acesta fiind probabil primul exemplu cunoscut. Ca termen, Deus ex machina înseamnă că, atunci când există o problemă de nerezolvat, intervine o cale de rezolvare neașteptată; se ivește o nouă ocazie, un personaj, o abilitate sau un obiect care funcționează pentru a rezolva într-un mod surprinzător o situație nerezolvabilă într-o narațiune. Literal, înseamnă „un zeu într-o mașinărie“: în piesele antice, zeul ca personaj cobora pe scenă cu ajutorul unei mașinării. Atunci când povestea devenea foarte complexă, iar autorul nu putea găsi o soluție interesantă, zeii, ca personaje, interveneau în desfășurarea acțiunii, fiind coborâți pe scenă cu ajutorul unei macarale. ${ }^{2}$

Dacă ne întoarcem la ideea avangardistă de unificare a disciplinelor artei, Richard Wagner trebuie menționat ca pionier al acestui concept. În eseul său „Lucrarea de artă a viitorului“

1. Oskar Schlemmer, „Man and Art Figure“, în: Johannes Birringer, Media and Performance: Along the Border, Baltimore, John Hopkins University Press, 1998, p. 45.

2. Steve Dixon, Barry Smith, Digital Performance. A History of New Media in Theater, Dance, Performance Art, and Installation, Massachusetts, The MIT Press, 2007, p. 23. 
(1849), el propune o noțiune nouă în care muzica, teatrul, poezia, iluminarea, arta vizuală și cântecul se pot uni și crea forme multidisciplinare de spectacol. Această nouă noțiune se numește Gesamtkunstwerk (opera de artă totală).

Viziunea lui Wagner, exprimată în scrieri precum „Opera de artă a viitorului“ (1849), dorea unificarea multiplelor forme ale artei: teatrul, muzica, dansul, cântul, poezia dramatică, designul, iluminarea și artele vizuale. Această concepție ocupă un loc central în dezvoltarea spectacolului multimedia, atât din punctul de vedere al promovării noțiunii unui spectacol teatral grandios, cât și din cel al modelului de convergență care unește Opera Totală de Artă cu înțelegerea contemporană a computerului ca un instrument care unifică toate tipurile de media - text, imagine, sunet, video - într-o singură interfață. Aplicând conceptul operei de artă totală în dramele sale muzicale, Wagner căuta nu doar să realizeze o sinteză a tuturor artelor, ci inclusiv o imersiune a publicului în spectacol, un țel pe care dorește să îl atingă și arta multimedia contemporană. Pentru aceasta, el s-a folosit de o serie de strategii artistice și tehnice, de la ascunderea orchestrei din văzul publicului la folosirea de leitmotive muzicale repetitive hipnotizatoare. Pentru a fi cât mai aproape de scopul său, Wagner a construit un teatru de la zero, Bayreuth Festspielhaus, deschis în 1876, cu o sală de spectacole construită în formă de evantai, pentru a permite publicului să aibă aceeași perspectivă asupra scenei indiferent de poziționarea în sală, și care elimina orice posibilitate de obturare a vederii din cauza stâlpilor de susținere, balcoanelor sau boxelor. Acesta era, de asemenea, un teatru sofisticat din punct de vedere acustic, utilizând cele mai noi inovații în materie de tehnologie pentru intensificarea iluziei imaginilor mitice create de Wagner. Instrumentiștii din orchestră erau aranjați pe niște trepte aflate dedesubtul scenei, un acoperiș imens curbat purtând sunetul direct pe scenă. Spre deosebire de sălile tradiționale de spectacol, aici muzica orchestrei era transmisă în primă instanță pe scenă, unde se contopea cu vocile artiștilor, pentru ca doar apoi să fie transmisă în sală, audienței. Wagner a fost, așadar, primul care a realizat un sistem de mixare audio sofisticat, care rămâne și în zilele noastre unic și puternic. 
Se consideră, astfel, că Wagner a avut o mare influență asupra teatrului experimental, viziunea totalizatoare a „operei de artă totale" generând un impact profund asupra teoriilor și practicii artelor spectacolului din secolul XX. În anul 1919, artistul dadaist Kurt Schwitters scria: „cer mobilizarea completă a tuturor forțelor artistice pentru crearea Operei de Artă Totale... cer incluziunea tuturor materialelor... cer revizuirea tuturor teatrelor lumii“. ${ }^{3}$ In anul 1930, Meyerhold nota în Reconstrucția teatrului că, deși ideile lui Wagner au fost privite drept „complet utopice“, cu timpul viziunea acestuia cu privire la fuziunea tuturor artelor este exact felul în care ar trebui să arate o producție. ${ }^{4}$ Așa cum Wagner își construise teatrul, și Meyerhold propunea renunțarea la scena de tip „cutie“ și adoptarea unui spațiu în care să nu existe o diviziune a audienței. ${ }^{5}$

Printre influențele performance-ului digital se numără experimentele realizate de către avangarda modernistă a începutului de secol XX - futurismul, constructivismul, expresionismul, dadaismul și suprarealismul. Futurismul, prima mișcare de avangardă a secolului XX, are o poziție centrală în descendența performance-ului, iar, după spusele lui Steve Dixon, originea acestuia este legată „precis și inextricabil de filosofiile, estetica și practicile mișcării futuriste“. 6 Există asemănări puternice între performance-ul digital și unele mișcări ale avangardei începutului de secol XX, precum futurismul, care a luat naștere într-o perioadă de „revoluție“ tehnologică, revoluție comparabilă cu cea digitală din anii 1990, când „o estetică inginerească avea să definească avangarda în arhitectură și artă“.7 După spusele lui Andreas Huyssen, „,nu există un factor de o mai mare importanță care să fi influențat apariția noii avangarde la fel de mult ca tehnologia,

3. Apud Oliver Grau, Virtual Art: From Illusion To Immersion, Massachusetts, MIT Press, 2003, p. 145.

4. Apud Edward Braun, Meyerhold on Theatre, London, Methuen, 1969, p. 254.

5. Ibidem, p. 257.

6. Steve Dixon, Barry Smith, Digital Performance..., ed. cit., p. 47.

7. R. L. Rutsky, High Techne: Art and Technology from the Machine 
care nu doar că a stârnit imaginația artiștilor, dar a pătruns până în miezul operei în sine“.8

Futuriștii italieni de la începutul secolului XX căutau să realizeze o îmbinare multimedia a tuturor ramurilor artei, precum și îmbinarea acesteia cu tehnologia. În anul 1916, acestei idei de Operă de Artă Totală i-a fost conferită inclusiv o formulă matematică - în același mod în care unui eveniment virtual contemporan îi este conferit un cod realizat de un computer -, care a primit denumirea de Teatru Sintetic: pictura + sculptura + dinamismul plastic + cuvintele în libertate + zgomotul compus (intonarumori) + arhitectura = teatrul sintetic. Steve Dixon este de părere că, deși arta vizuală futuristă ocupă un loc însemnat în istoria artei, „performance-ul futurist a fost în ceea mai mare parte trecut cu vederea în istoria teatrului, în ciuda faptului că multe dintre cele mai importante manifeste futuriste se adresau în mod specific teatrului și mai puțin artelor vizuale. “9 Manifestul din 1915 intitulat Teatrul sintetic futurist sublinia cu litere mari faptul că „ORICE ARE O VALOARE ESTE TEATRAL“, iar figurile-cheie ale futurismului și-au dedicat mare parte a creației artistice performance-ului, inclusiv liderul acestuia, Filippo Tommaso Marinetti, care era, în primul rând, un dramaturg.

Istoricul de artă Giovanni Lista ${ }^{10}$ descrie futurismul ca având asocieri directe cu felul în care vedem astăzi computerul și spațiul virtual ca pe un loc dedicat evoluției personale și culturale, un proiect antropologic, într-un fel, al noului om față în față cu lumea mașinilor, a vitezei și a tehnologiei, într-o permanentă revoluție culturală care introduce arta în viața de zi cu zi, promovând elementul de noutate în detrimentul conformismului inerent tradiției.

Futurismul este, în primul rând, o filosofie a transformării, exprimată printr-un activism care traversează epocile și prin celebrarea vieții ca o constantă evoluție a ființei. Un

Aesthetic to the Posthuman, Minneapolis, University of Minnesota Press, 1999, p. 81.

8. Apud R.L. Rutsky, High Techne, ed. cit., p. 76.

9. Steve Dixon, Barry Smith, Digital Performance..., ed. cit., p. 48.

10. Giovanni Lista, Futurism, Paris, Éditions Pierre Terrail, 2001, p. 10. 
futurist de astăzi, notează Steve Dixon, ar fi un fan al imaginilor generate pe calculator. Asta cu atât mai mult cu cât elemente centrale filosofice și stilistice ale performance-ului futurist, ca dinamismul plastic, „compresia, simultaneitatea și implicarea audienței“, ${ }^{11}$ sunt noțiuni de bază ale performance-ului digital contemporan.

Inovații futuriste precum desfășurarea de acțiuni simultane, în paralel, pe scenă pot fi cu ușurință asemănate cu teatrul interactiv și performance-urile distribuite pe DVDuri care oferă publicului posibilitatea de a alege pe ce fir al acțiunii să se concentreze. Piesa lui Marinetti, Simultaneitate (1915), conținea două fire narative jucate în paralel, iar pentru Vasele comunicante (1916), acțiunea se desfășura în trei locuri diferite. În ambele piese, barierele dintre lumi distincte sunt spulberate, iar personajele trec dintr-una în cealaltă, invadând alte spații.

O altă asemănare a spectacolelor multimedia cu futurismul o constituie principiul „divizionismului“ și similarul lui din pictură, „pensulația/tușa divizată“. Tehnicile aplicate în pictura futuristă și în fotografie pentru descrierea mișcării în relație cu timpul au paralele în efectele de mișcare digitală și suprapunerea a multiple imagini în spectacolele de dans și teatru contemporan. În multe picturi futuriste, diferite stadii ale mișcării erau reprezentate pe același suport, având ca rezultat crearea unei extensii a mișcării, difuză și dinamică. Câinele din pictura lui Giacomo Balla, Dinamismul unui câine in mișcare (1912), de exemplu, este reprezentat într-o mișcare continuă; coada lui e pictată în nouă poziții diferite, fragmente ale mișcării complete, picioarele din spate se disting în șapte poziții, printre alte tușe neclare care reprezintă același lucru, iar picioarele din față sunt imposibil de văzut clar, sunt doar o formă nedefinită.

Fotografia futuristă, cunoscută sub numele de ,cronofotografie“ sau „dinamism fotografic“, căuta de asemenea să capteze și să reveleze „liniile de forță“ ale mișcării, așa cum se succedă ele în timp. Frații italieni Anton Giulio și Arturo

11. Ibidem, p. 10.13. Ibidem, p. 12. 
Bragaglia au realizat numeroase fotografii prin expunerea negativelor pentru câteva secunde pentru a surprinde clar punctul de început și de sfârșit al mișcării, cu zonele intermediare neclare. Mișcarea temporară era așadar captată în fotografie, chipurile și corpurile oamenilor părând că se lichefiază, asemenea unor apariții fantomatice. Astăzi, efectele stroboscopice de mișcare și ,dizolvarea“ formelor corpului asociate esteticii futuriste sunt adesea folosite în spectacolele multimedia, un exemplu relevant în acest sens fiind efectele din spectacolul Les Entrailles de Narcisse (2001) al lui Bud Blumenthal, în care corpul uman pare a se diviza și a se spulbera.

Futuriștii se foloseau de obiectivul aparatului de fotografiat sau de filmat pentru a arăta o nouă viziune asupra lumii, una mecanică, capabilă să observe și să conserve timpul și spațiul într-un mod imposibil pentru ochiul uman, iar ca o continuare firească, în era computerului, noile tehnologii permit ca această viziune să fie realizată pe deplin și cu relativă ușurință.

Manifestul lui Enrico Prampolini din 1915, Scenografia futuristă, descrie scene iluminate și corpuri virtuale care au devenit realitate acum, la un secol distanță: „Scena nu va mai fi un fundal colorat, ci o arhitectură electromecanică lipsită de culoare, adusă la viață prin emanațiile cromatice ale unei surse luminoase. [...] În locul scenei iluminate, să creăm scena luminoasă: expresii de lumină care vor iradia culorile cerute de acțiunea dramatică, cu o deplină putere emoțională. În epoca futurismului pe deplin realizabil, vom vedea dinamica arhitectură de lumini a scenei emanând din incandescențe cromatice care, escaladând dramatic sau revelându-se voluptuos, vor trezi în spectator noi senzații și emoții. Vibrații, forme luminoase (produse de curenți electrici și gaze colorate) se vor zbate într-o mișcare dinamică, iar aceste autentice gaze-actor ale unui teatru necunoscut vor înlocui oamenii pe scenă“. ${ }^{12}$ Felul în care el descrie înlocuirea actorului cu forme luminoase este similar cu modul în care spectacolul digital se folosește de forme umane generate de computer, inclusiv de inteligența artificială (AI).

12. Dixon Steve, Smith Barry, Digital Performance..., ed. cit., p. 54. 
Hibridizarea spectacolului și varietatea de mijloace digitale folosite dau naștere unor noi moduri de percepție și conștiință, notează Steve Dixon, iar cea mai mare contribuție a tehnologiei adusă artei este îmbunătățirea și reconfigurarea potențialului creativ estetic, care constă în interacțiunea cu corpul fizic, iar nu abandonarea acestuia. În acest spațiu aflat între fizic și virtual este de părere Dixon că se nasc oportunitățile pentru noi forme și practici experimentale. ${ }^{13}$

Spectacolele multimedia și arta digitală reprezintă așadar o avangardă emergentă, care a luat startul, dar nu a ajuns încă să exprime pe deplin preocuparea esențială a avangardei, și anume aceea de a declanșa schimbări sociale majore și de a transforma felul în care arta funcționează în și se raportează la societate. Din acest punct de vedere, artiștii contemporani ar trebui să folosească tehnologiile contemporane mai puțin sub formă de experiment și mai degrabă cu scopul unei reconfigurări fundamentale artistice și sociale.

\section{Bibiografie:}

BIRRINGER, Johannes, Media and Performance: Along the Border, Baltimore, John Hopkins University Press, 1998.

Braun, Edward, Meyerhold on Theatre, London, Methuen, 1969.

Dixon, Steve; SMITH, Barry, Digital Performance, a History of New Media in Theater, Dance, Performance Art, and Installation, Massachusetts, The MIT Press, 2007.

GRAU, Oliver, Virtual Art: From Illusion To Immersion, Messachusetts, MIT Press, 2003.

LISTA, Giovanni, Futurism, Paris, Éditions Pierre Terrail, 2001.

RUTSKy, R.L., High Techne: Art and Technology from the Machine Aesthetic to the Posthuman, Minneapolis, University of Minnesota Press, 1999.

13. Ibidem, p. 12. 